\title{
Thinking and Exploration in Photographic Practical Teaching
}

\author{
Ning ZHANG ${ }^{1, a}$, Feng WANG $^{2, b}$, Jia MENG ${ }^{2, c}$ \\ ${ }^{1}$ School of Fashion, Dalian Polytechnic University, Dalian 116003, China \\ ${ }^{2}$ College of Civil Engineering, Dalian Nationalities University, Dalian 116650, China \\ aemail: zhangninglady@sina.com, bemail:win_0803@163.com, cemail:mengj2015@163.com
}

Keywords: Photography; practical teaching; application type talents; popular education

\begin{abstract}
The photographic education in domestic schools of higher learning has a common problem, that is, the practicing ability and innovation ability of students is unable to meet social requirements. A problem arises between the education in schools of higher learning and social "supply and demand" and the education in photographic schools of higher learning is unable to meet the time development. Through photographic practice and exploration for 10 plus years, it is presented that the current tasks for photographic education are to innovate the practical teaching mode, cultivate application, composite type talents with an innovative spirit to meet the social requirements. The article presents reform and exploration in photographic practical teaching mode in such two aspects as identifying photographic practical teaching construction thinking and establishing such a double rail crossing photographic practical teaching system as "advancement practice + open practice” with a good teaching effect having been received in practical teaching.
\end{abstract}

\section{Introduction}

A common characteristic of the teaching in the photographic specialty in domestic schools of higher learning is emphasis on practice and refraining from empty talk. There is no doubt that this is a good tradition and it meets the characteristics of the photographic specialty. However, in the photographic field, especially in the commercial photographic industry, there is an unarguable fact that the practicing ability of current year's graduates is not as good as some young photographic practitioners receiving no higher education. Such an awkward situation refracts intuitionally a common problem in domestic photographic schools of higher learning: the practicing ability and innovation ability of students is unable to meet the social requirement and a problem arises between the "supply and demand" of schools of higher learning and society. Therefore, innovating the practical teaching mode and improving the practical teaching effect is a prime topic for the teaching reform in the photographic teaching in schools of higher learning; a crucial link to cultivate application and innovation type talents with an innovation spirit and pioneering ability.

\section{Enhancing and Identifying Photographic Practical Teaching Construction Thinking}

From 2000 when Dalian Polytechnic University established the photographic department until now, our photographic education has had a great improvement in both scale and quality. Through tracking to and receiving feedbacks from a great number of graduates, investigation to the photographic specialty in other both colleges and universities, listening to the opinions of industrial front-end experts and repeated demonstrations and discussions, such a talent cultivation scheme as "being aimed to cultivate excellent photographic workers and application type image talents using image as the artistic language and having a high visual aesthetic level” was finally determined, and a practical teaching system to cultivate application type talents is to be constructed.

The practical teaching system setup in the photographic specialty in domestic schools of higher learning are roughly the same, including such two parts as course practice and centralized practice links. The centralized practice link consists of such parts as photographic scene hunting, graduation practice, graduation creation, etc. According to the past teaching philosophy, the practical teaching course is only the auxiliary part of theoretical course, which helps students master and comprehend 
theoretical knowledge through some auxiliary operation trainings. But in today, the shortcomings existing in such a practical teaching system are appearing gradually: firstly, course practice and centralized practice is lack of transition in between, and it is very hard for students to integrate and apply the knowledge of multiple fundamental practical courses effectively; secondly, students are unable to complete the shift from "job mode" to "work mode" before graduation; thirdly, such a unified teaching system is not set up taking students as the main body, unable to meet the demands of students at different ability levels better, letting alone achieve really teaching of students in accordance with their aptitude, focal selecting of top-notch students. Especially for those students with a prominent ability, their innovation ability is not sufficiently given play to and upgraded.

In view of the above problems, we have designed such a double rail crossing photographic practical teaching system as "advancement practice + open practice" by starting from the objective to cultivate innovative, practical type photographic talents and according to such thinking as "taking ability cultivation as the core, combining theoretical teaching and practical teaching organically, level progression, combination of longitudinal and transverse work, benign interaction" and the progression law for fundamental, comprehensive, design, innovative teaching.

\section{Advancement Practical Teaching System}

The development practical teaching includes the "fundamental cultivation period", "specialty expansion period", "specialty integration period”.

\section{"Fundamental cultivation period"_fundamental practical teaching auxiliary to theoretical course}

The "fundamental cultivation period" means the practical teaching course as an auxiliary part to theoretical course, which helps students master and comprehend theoretical knowledge through some auxiliary operation trainings and is a fundamental practice. The fundamental cultivation period includes a lot of fundamental photographic courses: Fundamental Photography, Light Use in Photographing, Photographic Composition, Still Photography, Figure Photography, Building Photography, etc. Each course pays attention to the effective combination of theoretical teaching and practical teaching. The practical teaching deepens the comprehension of students about abstract knowledge, and students experience the significance of theoretical guidance to practice in practice. When the practical training "points" seeming to be independent in these courses are linked together, students acquire the foundation for study in the next stage.

\section{“Specialty expansion period”__ comprehensive practical teaching taking course module as something dominant}

The "specialty expansion period" consists of two parts: comprehensive practice I taking course module as something dominant, comprehensive practice II taking social practice and specialty investigation as something dominant.

Comprehensive practice I taking course module as something dominant is a "comprehensive training on theme photographing”. The courses include: Special Figure Interview, Advertisement Photography, Fashion Photography, etc., which have a very definite and clear requirement that is quite difficult. The difference from the practical teaching in the "fundamental cultivation period" is that students confront a greater challenge: a lot of problems such as the complicated operation of such hardware as photographic equipment, lamps, etc., the arrangement of settings and props, the mobilization of and communication with models, the coordination with dresser, etc. Students have transited from fundamental practical training to comprehensive training. As far as technical ability training is concerned, this stage is a summary of the practical course during the "fundamental cultivation period". However, technical and skill training is not all for photographic teaching. As we mentioned earlier, a supply and demand conflict arises between the graduates exported by schools of higher learning and the demand of social enterprise. The practicing ability and innovation ability of the graduates from photography specialty cultivated by us are unable to meet the social demand. The setup of the "theme photographic comprehensive training" is right an effective means to solve this problem. Through the "them photographic comprehensive training", students are allowed to experience the change from "job mode" to "work mode", and the teaching focus has shifted from 
knowledge and technical lecturing to comprehensive practicing ability cultivation under a special condition and a special limitation.

Take Figure Special Photographing Training as an example, the course requires students to interview and represent by image a figure (a group of figures). On basis of a sufficient communication, incorporate personal knowledge about the object and determine the main body and scheme of image representation. In training requirement, firstly, initial communication should be prepared in a planned manner after selecting the figure object, including such contents as purpose, manner, discussion, etc. Secondly, do complete text collation, including giving an account of the viewpoints of the object and explanation of personal viewpoints. Secondly, list written plans, predicted problems and the methods to solve them, what an individual has learned. Finally, use proper image language according to personal originality to complete a group of pictures. It is required to go beyond figure photographing concept in a common sense, consider relevant things and individual viewpoints concurrently while representing the image of a figure.

Photography is a subject with a strong applicability. Therefore, in teaching process, it is required to maintain a close contact with relevant industries, establish a practice base, make a sufficient use of these social resources to provide a good practice condition for students better and enhance the social practice and application ability of students constantly. At the same time, we can invite experienced experts and practitioners in enterprises and industries over to participate in guiding students to practice .This is an effective manner to supplement the teachers in schools of higher learning who are lack of practical experience and can improve significantly the teaching quality.

\section{Specialty integration period_explore graduation design teaching practice emphasizing both research and practice}

The target system and evaluation standard between the photographic teaching in schools of higher learning and social photographic practice are not fully the same, such as forward-looking in topic selection, innovative in conception, in-depth in research, etc. To establish effectively a good "supply and demand" relation between schools and enterprises, it is imperative to take the social demand as the guide in the graduation design link, emphasize both cultivation of students' ability and students' research to image and have a strict control over graduation design works showing photographic practical ability and theses showing research ability result.

\section{Open Practical Teaching System}

\section{Hardware guarantee for opening practical teaching system}

Improving practical teaching environment and practical teaching facilities is the foundation for promoting with a great effort the education quality. Take Dalian Polytechnic University as an example, for the past ten plus years, the school has invested more than RMB 3 million yuan successively in laboratory construction and renovation. It established 7 photographic experiment centers, purchased a lot of experimenting equipment, upgraded the school-running strength of the photographic specialty and ensures the quality of practical teaching. Such teaching equipment and data provide a strong support for realizing such a double-rail crossing photographic practical teaching system as "advancement practice + open practice".

Establish an open practical teaching system characterized by "teaching of students in accordance with their aptitude", "interest cultivation" and "focal selection of top-notch students”

Open practical teaching is a free and open practical teaching system set up by taking students as the main body and mainly being based on such teaching viewpoints as "teaching of students in accordance with their aptitude", "interest cultivation" and "focal selection of top-notch students". Open practical teaching is not an out-of-order vacuum zone in management. Practical teaching emphasizes not only the independence of students, but also has to be orderly in design, distinct in level, clear in target with effect being in place. The open practical teaching starts from cultivating the interest of students in the specialty and opens up practical teaching into a development space for students to "create ideas - innovate - pioneer" through establishing a competitive incentive mechanism, a project guide mechanism, a typical demonstration mechanism, an agent project 
training mechanism, etc.

In open practical teaching mode exploration, teachers mobilize sufficiently the initiative of students to study, improve the innovation ability of students and have won honors constantly in domestic education field. Students attended the annual Pingyao International Large-scale Art Exhibition with the most influential power domestically in five consecutive years; the works of students also won special honors for times in domestic and foreign important contests. Only in recent five years, students won awards in photographic contests above provincial level for 92 person times; and won the title of "ten national best schools in photographic education" in 2011, 2012 and 2013 consecutively.

\section{Summary}

Contemporary photographic industry is developing rapidly. The traditional education manner being didactic, limiting to book knowledge, with theory divorcing from practice, being unable to give play to the activity and initiative of students has become unable to meet the time development. The photographic teaching mode requires a constant innovation. To summarize such a double rail crossing photographic education system as "advancement practice + open practice", reform the practical teaching system, it is imperative to deal with properly the following three relations: firstly, deal with properly the relation between fundamental theoretical teaching and practical teaching, improve the effectiveness and interest of practical teaching; secondly, deal with properly the relation between quality education and specialty education, the relation between general talent education and special talent education; thirdly, deal with properly the relation between university photographic practical education and practice in social photographic industry.

\section{Acknowledgement}

In this paper, the research was sponsored by the project of teaching reform and education quality evaluation of Liaoning Education Evaluation Association (Grant NO. PJHYYB15047) and the project of characteristic specialty construction of Dalian Nationalities University.

\section{References}

[1] Bingwu Qiao. Education on employment view of college students under the background of higher education popularization[J]. Educational Exploration, 2009, 2, 135-136.

[2] Longjiang Wang, Lu Yao, Chuan Wang. Commercial photography[M].Beijing:Higher Education Press, 2008, 1-3.

[3] Yanan Chen, Jiansheng Zhang. Study on reform of practical teaching system of visual communication design, environmental design[J]. Journal of Lanzhou Institute of Education, 2013,1, 133-134.

[4] Xiuying Hu. Research and practice on the design of engineering bidding simulation course. Sichuan Building Materials, 201238 (3) 255-256.

[5] Junjie Chen, Min Tian, Jingwen Zhang. Exploration and practice of the comprehensive experiment in project management[J]. Research and Exploration in Laboratory, 2010 (3) 130-132. 